\title{
Incidence and Antibiogram of Acinetobacter Causing Neonatal Sepsis Among Hospitalised Patients
}

Syeda Shahnoor Hasina Mamtaz ${ }^{{ }^{*}}$ Abu Hena Md. Saiful Karim Chowdhury ${ }^{2}$ Gulshan Ara Begum ${ }^{3}$

Asma Ferdousi ${ }^{4}$

Mohammad Shahab Uddin 5

${ }^{1}$ Department of Pediatrics Institute of Applied Health Science (IAHS)

Chattogram, Bangladesh.

${ }^{2}$ Department of Microbiology Chattogram Medical College

Chattogram, Bangladesh.

${ }^{3}$ Department of Pediatrics

Chattagram Maa Shishu-O-General Hospital

Chattogram, Bangladesh.

${ }^{4}$ Department of Pediatrics

Chattogram Medical College

Chattogram, Bangladesh.

${ }^{5}$ Department of Pediatrics

Marine City Medical College

Chattogram, Bangladesh.

${ }^{*}$ Correspondence to:

Dr. Syeda Shahnoor Hasina Mamtaz

Assistant Professor

Department of Pediatrics

Institute of Applied Health Science(IAHS)

Chattogram, Bangladesh.

Mobile : +8801819609568

Email:shahnoormamtaz@gmail.com

Date of Submission : 15.12 .2019

Date of Acceptance : 10.01 .2020

www.banglajol.info/index.php/CMOSHMC

\begin{abstract}
Background: Acinetobacter species are typical nosocomial pathogens causing infections and high mortality, almost exclusively in compromised hospitalized patients. Multidrug-resistant Acinetobacter spp. blood infection in the neonatal intensive care unit patients create a great problem in hospital settings. The study was done to detect prevalence of acinetobacter spp. as the causative agent of neonatal sepsis with its antibiogram.
\end{abstract}

Materials and methods: A total of 100 clinically suspected neonatal sepsis cases was enrolled in the study. Bacteriological profile and antibiotic sensitivity pattern of acinetobacter spp. were done accordingly.

Results: Among the 100 suspected neonatal sepsis cases, 28\% were culture positive and $72 \%$ were culture negative. Klebsiella species was the predominant isolated bacteria which was $53.58 \%$ followed by Acinetobacter spp. (14.28\%) E. coli(10.72\%) Pseudomonas spp. (7.14\%) S. aureus (7.14\%) \& Candida (7.14\%). Acinetobacter spp. showed $100 \%$ resistant to ampicillin, ciprofloxacin, gentamycin, amikacin, ceftazidime, cefotaxime \& cefepime, $75 \%$ resistant to meropenem \& 50\% sensitive to levofloxacin.

Conclusion: It is essential to conduct periodic bacteriological profile along with routine antimicrobial sensitivity testing time to time for effective management of neonatal sepsis.

Key words: Multidrug resistant; Acinetobacter species; Culture sensitivity.

\section{INTRODUCTION}

Acinetobacter, once considered as opportunistic pathogen of low virulence, has recently been emerged as an important nosocomial pathogen worldwide, mostly involving patients with impaired host defence, especially in intensive care units, neonatal units, and surgical wards ${ }^{1,2}$.

Neonatal sepsis is a clinical syndrome characterized by signs and symptoms of infection with or without accompanying bacteremia in the first month of life ${ }^{3}$. Incidence of neonatal bacterial sepsis varies from 1-4 per 1000 live birth in developed countries, with considerable fluctuation over time and with geographic variations ${ }^{4}$. Around one million deaths every year throughout the world are due to neonatal sepsis. In Bangladesh, currently, the neonatal mortality rate is 18.4 per 1000 live births which accounts for $60 \%$ of under five deaths ${ }^{5}$. Neonatal sepsis accounted $40.7 \%$ of total admitted cases and attributed about $19.0 \%$ of total neonatal death in Special Care Neonatal Unit of Chattogram Medical College Hospital ${ }^{6}$.

The uncertainty surrounding the clinical approach to treat neonatal sepsis can be minimized by periodic epidemiological survey of etiological agents and their antibiotic sensitivity pattern leading to recognition of the most frequently encountered pathogens in a particular neonatal setting. Micro-organisms implicated in neonatal sepsis have developed increased drug resistance to commonly used antibiotics and thus making treatment extremely difficult. 
Along with other organisms such as Klebsiella spp, E. coli, Staphylococcus aureus, Pseudomonas spp, and Salmonella spp, Acinetobacter species are gaining importance as potential pathogens in neonatal septicemia because of their frequent isolation and multi-drug resistance ${ }^{7}$. The present study highlights Acinetobacter spp. as an important pathogens in neonatal blood stream infection.

\section{MATERIALS AND METHODS}

This hospital based observational study was carried out in Special Care Neonatal Unit (SCANU) of Chattogram Medical College Hospital during the period of January-December 2015.

\section{Inclusion criteria ${ }^{4}$.}

Any neonate having clinical signs/symptoms of sepsis according to Integrated Management of Childhood Illness (IMCI) and World Health Organisation (WHO).

\section{Exclusion criteria $^{8}$ :}

i) Neonates having extreme prematurity (Less than 30 weeks of gestational age)

ii) Birth weight less than $1000 \mathrm{gm}$.

iii) Gross congenital anomalies.

Blood samples were taken from 100 suspected neonatal sepsis cases after taking both written and verbal consents from the attendants of the patients. Under all aseptic precautions, at least $3 \mathrm{ml}$ of blood from each neonate was collected. Blood was introduced in the blood culture bottle containing $10 \mathrm{ml}$ of trypticase soy broth. The blood culture bottles were then transported immediately to the laboratory of the department of microbiology, Chattogram Medical College for culture and antibiotic sensitivity testing ${ }^{9}$.

\section{RESULTS}

Among the 100 suspected neonatal sepsis cases, 28\% were culture positive and $72 \%$ were culture negative.

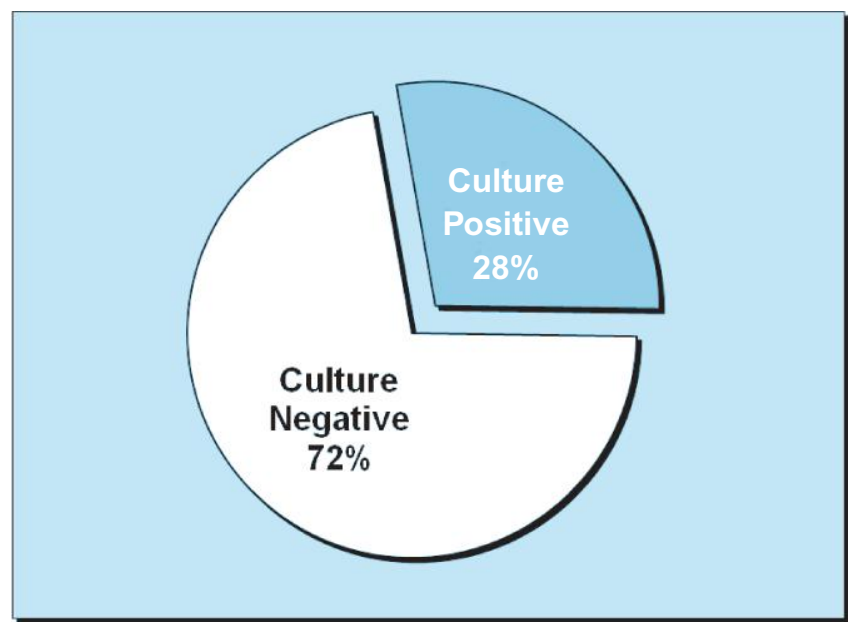

Figure 1 : Distribution of the culture proven sepsis

Distribution of isolates among the culture proven sepsis showed Klebsiella spp. (53.58\%) was predominant isolated organisms in the study, followed by Acinetobacter spp. (14.28 \%) E. coli (10.72\%) Pseudomonas spp. (7.14\%) Staph. aureus (7.14\%) \& Candida spp. (7.14\%) respectively.
Table I : Distribution of causative organisms

\begin{tabular}{lcc} 
Name of organisms & Number & Percentage \\
Klebsiella spp. & 15 & 53.58 \\
Acinetobacter spp. & 04 & 14.28 \\
E. coli & 03 & 10.72 \\
S. aureus & 02 & 7.14 \\
Pseudomonas spp. & 02 & 7.14 \\
Candida spp. & 02 & 7.14 \\
Total & 28 & 100.0 \\
\hline
\end{tabular}

Antibiotic sensitivity pattern of isolated bacteria of neonatal sepsis showed that acinetobacter spp. was $100 \%$ resistant to ampicillin, ciprofloxacin, gentamycin, amikacin, ceftazidime, cefotaxime \& cefepime, $75 \%$ resistant to meropenem \& 50\% sensitive to levofloxacin.

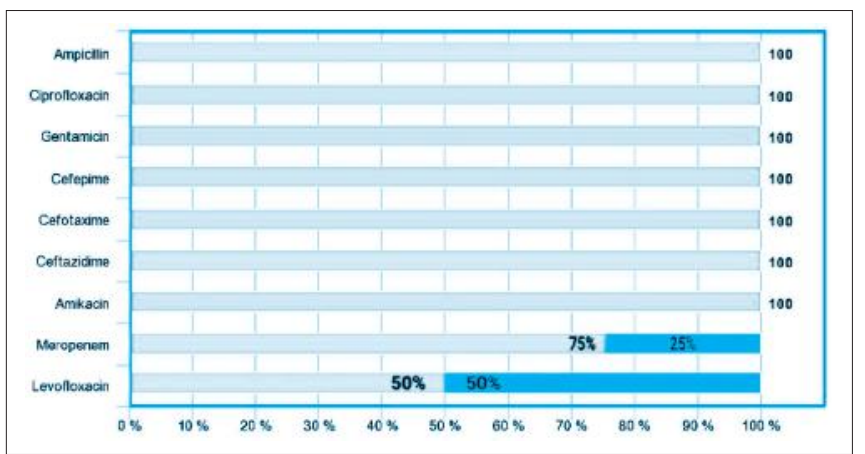

Figure 2 : Sensitivity pattern of acinetobacter spp. against different antimicrobial agents

\section{DISCUSSION}

Neonatal sepsis is one of the major health problems in developing countries including Bangladesh. Early diagnosis of neonatal sepsis is primarily based on clinical evaluation but it requires clinico-pathological \& microbiological correlation ${ }^{10}$. In our study, among the 100 suspected neonatal sepsis cases, culture proven sepsis was $28 \%$ and culture negative sepsis was $72 \%$. Similar to our study, Barua et al. showed blood culture positivity to be $32 \%$ in their study done in the same institute ${ }^{11}$.

A number of organisms is associated with neonatal sepsis and bacterial pathogens may vary from one country to another and within a country from one hospital or region to another. These organisms may even vary at different times within the same place. In developed countries Group B streptococcus (GBS) E. coli and Listeria monocytogenes are the most common causes of neonatal sepsis, however, in developing countries these bacteria are replaced by gram-negative bacilli, CoagulaseNegative Staphylococcus (CONS) and others ${ }^{12}$.

Among the isolates from blood culture, Klebsiella spp. $(53.58 \%)$ was the predominant isolaeted organism in our study followed by Acinetobacter spp. (14.28\%) E. coli (10.72\%) Pseudomonas spp., Staph. aureus \& Candida was $7.14 \%$ each. Acinetobacter spp was second most isolated organism in our study which is in accordance with the study done by Jayashima 
et al. $(23 \%)^{13}$. Incidence of neonatal sepcicaemia by acinetobacter spp in study done by Barua et al. was $14.58 \%$ and by Begum \& Fatema was $10.8 \%{ }^{11,14}$. The prevalence of acinetobacter spp. varies somewhat by country and by specimen site but has generally increased worldwide in the past two decades. Although there are significant differences in acinetobacter antimicrobial resistance pattern according to species, country of isolation, and region, the overall trend is one of increasing resistance ${ }^{15}$.

Searching antibiotic sensitivity pattern, we found that acinetobacter spp. was $100 \%$ resistant to ampicillin, ciprofloxacin, gentamycin, amikacin, ceftazidime, cefotaxime \& cefepime, $75 \%$ resistant to meropenem \& $50 \%$ sensitive to levofloxacin. Similar to us Mannan et al. found acinetobacter spp., $100 \%$ resistant to ampicillin, gentamycin, cefotaxime \& piperacilin-tezobactam but highly sensitive to colistin $(86 \%)$, followed by imipenen/meropenem (57\%), amikacin (29\%) and ciprofloxacin $^{16}$.

The occurrence of acinetobacter spp. in neonatal sepsis is of great concern. The presence 45 resistance genes in acinetobacter spp. was recently described, some of the genes had not previously been reported to be associated with acinetobacter and resistance of this organism may be due to presence of multidrug resistance efflux pump, alteration in antibiotic targets, production of antibiotic altering enzymes like cephalosporinases, carbapenemases, aminoglycosede modifying enzymes, limited antibiotic entry like porin mutations, limited porin production etc. Acinetobacter should be added to the list of organisms causing severe nosocomial infection in neonatal intensive care units. Multi-drug resistant nosocomial Acinetobacter septicemia may cause severe clinical disease in neonates that is associated with a high mortality ${ }^{15}$.

\section{CONCLUSION}

The increase in the infection rate due to a particular pathogen may be due to lapses in infection-control measures, resulting in an increase in cross-transmission between patients. Therefore, continuous bacteriological surveillance, implementation of infection control policies, careful disinfection of intensive care equipment, and rational antibiotic use are required to control such infections. Effective therapy must be individualized to reflect these differences in regional, local and specific hospital resistance patterns.

\section{DISCLOSURE}

All the authors declared no competing interest. 


\section{REFERENCES}

1. Bergogne-Berezin E, Towner KJ. Acinetobacter species as nosocomial pathogens: Microbiological, clinical, and epidemiological features. Clin Microbiol Rev. 1996;9:148-165.

2. Melamed R, Greenberg D, Porat N, Karplus M, Zmora E, Golan A et al. Successful control of an Acinetobacter baumannii outbreak in a neonatal intensive care unit. J Hosp Infect. 2003;53:31-38.

3. AIIMS protocol 2014 on Sepsis in the Newborn. In R Agarwal, AK Deorari, VK paul. (Eds.) AIIMS protocol in Neonatology. CBS publishers. Delhi. 2014;1-13 viewed on 12 December 2015 at www.newbornwhocc.org.

4. Stoll BJ, Shane AL. Infections of the neonatal infants in RM Kliegman, BF Stanton, JWS Geme, NF Schor. Nelson textbook of pediatrics. $20^{\text {th }}$ edn. Elsevier. Philadelphia. 2016;1:909-925.

5. Bangladesh Demographic and Health Survey - Preliminary report 2014. Viewed 10 November 2016, www.DHSprogram.com.

6. Das JC, Barua CC, Uddin G, Islam R, Chowdhury A, Barua SK et al. Admission profile and its outcome in special care neonatal unit (SCANU) of Chattogram Medical College Hospital, JCMCTA, CMCTACON 2014. $1^{\text {st }}$ International Scientific Conference. $27^{\text {th }}-30^{\text {th }}$ October.2014;32.

7. Vinodkumar CS, Neelagund YF. Acinetobacter septicaemia in neonates. Indian J Med Microbiol. 2004;22:71.

8. Mustafa M, Ahmed SL. Bacteriological profile and antibiotic susceptibility patterns in neonatal septicemia in view of emerging drug resistance. J Med Allied Sci. 2014;4(1):02-08.

9. Collee JG, Marr W. Culture of bacteria. In JG Collee, AG Fraser, BP Marmion, A Simmons (Eds). Mackie and McCartney Practical Medical Microbiology. $14^{\text {th }}$ ed. Churchill Livingstone. New York. 1996:121-124.

10. Khair KB, Rahman MA, Sultana T, Roy CK, Rahman, MQ Shahidullah M et al. Role of hematological scoring system in early diagnosis of neonatal septicemia. BSMMUJ. 2010;3:62-67.

11. Barua CC, Mahmud NU, Chowdhury PK, Das JC, Barua S, Chowdhury N. Sensitivity pattern of causative agent in neonatal septicemia at Special Care Newborn Unit (SCANU) Chattogram Medical College Hospital. JCMCTA, CAMCTACON 2014. $1^{\text {st }}$ International Scientific Conference $27^{\text {th }}-30^{\text {th }}$ October. 2014;31.

12. Begum M, Hassan M, Haque ZSM, Jahan N, Chowdhury K, Rob AWS. Study of bacteriological pathogen causing neonatal sepsis at NICU in Ad-din Medical College Hospital. Northern International Medical College Journal. 2013;5(1):297-300.

13. Jayasimha VL, Raghukumar KG, Vinod Kumar CS, Patil SS, Basavarajappa KG. Neonatal septicemia and antibiogram: Paediatrician's Challenge. RGUHS Med Sciences. 2017; 7(1):12-15.

14. Begum S, Fatema K. Drug Resistant organism in early onset and late onset neonatal septisis in a tertiary care hospital. Journal of Clinical Neonatology. 2016; 5(4):254-258 viewed on 12 March, 2019 at http://www.jcnonweb.com.

15. Allen DM, Hartman BJ. Acinetobacter Species in GL Mandell, JE Bennett \& R Dolin, (Eds), Mandell, Doglus and Bennett's principles and practice of infectious diseases, $7^{\text {th }}$ edn, Churchill Livingstone, Philadelphia. 2015;2881-2885.

16. Mannan MA, Iqbal S, Karim SMR, Ahmed TU, Khan MHH, Ahamed AU et al. Bacterial isolates of early onset neonatal sepsis and their antibiotic susceptibility pattern. Chattogram Maa-O-Shishu Hospital Medical College Journal. 2018;17(1):03-08. Viewed on 05 July, 2019 at www.banglajol.info/index.php/CMOSHMCJ. 